\title{
Development of three-layered rumen escapable capsules for cattle
}

\author{
Tomohiro SEYAMA ${ }^{1) *}$, Hirofumi HIRAYASU ${ }^{1)}$, Kenji YAMAWAKI ${ }^{1)}$, Takuhiko ADACHI ${ }^{2)}$, Takayuki SUGIMOTO ${ }^{2)}$ \\ and Koji KASAI ${ }^{1)}$ \\ 1) Department of Environmental Research, Local Incorporated Administrative Agency Research Institute of Environment, Agriculture and \\ Fisheries, Osaka Prefecture, 442 Syakudo, Habikino, Osaka 583-0862, Japan \\ 2) Research and Development Department, Morishita Jintan Co. Ltd., 11-1 Tsudayamanote, 2-Chome, Hirakata, Osaka 573-0128, Japan
}

(Received 27 June 2016/Accepted 8 August 2016/Published online in J-STAGE 20 August 2016)

ABSTRACT. A new rumen escapable tool is presented for cattle in prospect of developing medical treatment or supplementing trace elements for disease prevention. This tool consists of a three-layered capsule that dissolves in the lower digestive tract, but not in the rumen. The capsule was manufactured by capsule-forming techniques through the use of liquid surface tension. This method does not involve hightemperature treatment, so the capsule can contain not only lipophilic substances but also hydrophilic or heat-sensitive substances. Furthermore, the capsule has a specific gravity of 1.3 and diameter of $6.0 \mathrm{~mm}$, which were previously shown to be appropriate to avoid rumination. The objective of this study was to confirm the effectiveness of the capsule pertinent to rumen escaping. In order to validate rumen escape, capsules containing $30 \mathrm{~g}$ of water-soluble vitamin (thiamine hydrochloride) per head were administered to four lactating cows assigned in a crossover trial. In the group administered encapsulated thiamine hydrochloride, blood thiamine levels increased from $12.4 \pm 1.03 \mathrm{ng} / \mathrm{ml}$ before administration to $54.8 \pm 2.21 \mathrm{ng} / \mathrm{ml}$ at $6 \mathrm{hr}$ following administration, whereas the level remained at $13.3 \pm 2.05 \mathrm{ng} / \mathrm{ml} \mathrm{in}$ the control group administered via aqueous solution. This indicates that the three-layered capsules passed through the rumen and dissolved in the lower digestive tract, thus functioning as a rumen escapable tool.

KEY WORDS: capsule, dairy cattle, water soluble vitamin

doi: 10.1292/jvms.16-0337; J. Vet. Med. Sci. 78(12): 1765-1769, 2016

Advances in the genetic improvement of dairy cows, especially the Holstein variety, have led to large increases in per capita milk production. Since it is necessary to balance nutrient intake to meet this increased milk production, a greater burden is placed on the body, including the metabolization of lipids and carbohydrates in the liver. Consequently, metabolic disorders have become more frequent and are now a significant problem for dairy management $[11,18]$. Metabolic diseases, such as ketosis, are primarily caused by a negative energy balance during early lactation [4].

Clinical and latent ketosis are major economic diseases, reducing milk production and also causing reproductive problems, such as an increase in the number of days open [5]. Ketosis is both prevented and treated by the intravenous administration of B vitamins and sugars [21]. However, cows are polygastric, and of their four stomachs, the first stomach (the rumen) contains $1-100$ billion microorganisms per gram. Consequently, even when B vitamins are administered orally, they are broken down by microorganisms, with as little as $52 \%$ of thiamine (VB1), $1 \%$ of riboflavin (VB2) and $3 \%$ of niacin (VB3) escaping the rumen [24]. Thus,

\footnotetext{
*Correspondence to: Seyama, T., Department of Environmental Research, Local Incorporated Administrative Agency Research Institute of Environment, Agriculture and Fisheries, Osaka Prefecture, 442 Syakudo, Habikino, Osaka 583-0862, Japan.

e-mail: seyama@mbox.kannousuiken-osaka.or.jp

(C)2016 The Japanese Society of Veterinary Science

This is an open-access article distributed under the terms of the Creative Commons Attribution Non-Commercial No Derivatives (by-nc-nd) License $<$ http://creativecommons.org/licenses/by-nc-nd/4.0/>.
}

intravenous or subcutaneous injections, or a rumen escapable feed must be used when administering these functional ingredients to cows.

Substances that have particularly high potential for decomposition by microbes in the rumen can be protected by coating with oil, enabling them to avoid degradation and reach the abomasum [3]. However, because this method involves the suspension of the administered substance in heattreated oils followed by solidification through cooling, it is difficult to achieve escaping using hydrophilic substances, such as water-soluble vitamins or medicine, or heat-sensitive substances, such as live microbial agents. More specifically, mixed hydrophilic substances treated in heated oil can be easily separated during solidification process. Also, heatsensitive substances are inactivated by hot melting oils. Therefore, in the present study, we developed a new rumen escapable tool for cattle, consisting of a three-layered capsule that can protect the contents from degradation by microorganisms and dilution in the massive rumen. The capsule is manufactured at room temperature so that hydrophilic or heat-sensitive substances can be contained without suffering any harmful heat effect. Encapsulated thiamine hydrochloride indicator was administered to lactating cows to verify that the capsules had escaped the rumen degradation and reached the lower gastrointestinal tract.

\section{MATERIALS AND METHODS}

Animals and diet: All animal procedures conformed to the guidelines of the local ethics committee (Animal Experimentation Department of the Local Inc. Administrative 
Agency Research Institute of Environment, Agriculture and Fisheries, Osaka Prefecture). Four Holstein cows of mean ( \pm standard deviation) weight $748 \mathrm{~kg}( \pm 31 \mathrm{~kg})$ and mean 332 days $( \pm 60)$ in milk were assigned to the test in a crossover trial. The test was carried out over two experimental periods. Each trial lasted for two days, and the trial interval was set for seven days. Animals were fed hay and concentrate separately in four installments at 06:30, 08:30, 10:30 and 14:30 daily (Table 1). Water was given ad libitum.

Capsule preparation: Capsules containing thiamine hydrochloride were manufactured by Morishita Jintan Co., Ltd. (Osaka, Japan) with a diameter of $6 \mathrm{~mm}$, specific gravity of 1.3 , approximately $160 \mathrm{mg}$ per capsule itself and a seamless three-layer structure according to the following procedure $[1,2,9]$ (Fig. 1): The core liquid suspension consisted of $25 \% \mathrm{w} / \mathrm{w}$ of thiamine hydrochloride and $25 \% \mathrm{w} / \mathrm{w}$ of titanium dioxide to regulate specific gravity, in liquid palm kernel oil having a melting point of $38^{\circ} \mathrm{C}$. The middle layer was designed to avoid degradation by stomach acid in the abomasum. It was produced from a liquid suspension consisting of $30 \% \mathrm{w} / \mathrm{w}$ titanium dioxide in hardened palm kernel oil having a melting point of $56.5^{\circ} \mathrm{C}$. The outer layer was intended to protect the middle layer from physical damage caused by jostling during transport. The composition of the outer aqueous suspension was as follows: 3.0\% w/w kappacarrageenan, $11.3 \% \mathrm{w} / \mathrm{w}$ cassava starch, $4.7 \% \mathrm{w} / \mathrm{w}$ sorbitol, $0.02 \% \mathrm{w} / \mathrm{w}$ locust bean gum, $1.4 \% \mathrm{w} / \mathrm{w}$ low-methoxy pectin, $0.23 \% \mathrm{w} / \mathrm{w}$ potassium chloride, $0.01 \% \mathrm{w} / \mathrm{w}$ calcium chloride, $0.09 \% \mathrm{w} / \mathrm{w}$ potassium hydrogen phosphate, $0.28 \% \mathrm{w} / \mathrm{w}$ potassium dihydrogen phosphate and $2.3 \% \mathrm{w} / \mathrm{w}$ titanium dioxide. These three types of suspension were applied via an encapsulation machine equipped a triple concentric nozzle. The core, middle and outer layers of the liquid suspension were simultaneously ejected (via the innermost, intermediate and outermost nozzles, respectively) to a flowing-oil chamber. The suspension formed a spherical capsule with three layers via its own surface tension in oil. The obtained wet capsules were dried at $20^{\circ} \mathrm{C}$ and $22.6 \%$ relative humidity on a rotating fluidized bed, thereby solidifying to form threelayer capsules. The polysaccharide (kappa-carrageenan, cassava starch, locust bean gum and low-methoxy pectin), sugar alcohol (sorbitol) and salts (potassium chloride, calcium chloride, potassium hydrogen phosphate and potassium dihydrogen phosphate) comprised in the outer thin layer of the capsule are commonly used for food additive and authorized feeding to cattle by Inc. Administrative Agency Food and Agricultural Materials Inspection Center in Japan. The palm kernel oil comprised in the middle layer and core are used for feed of cattle, and also, authorized. Titanium dioxide to regulate specific gravity comprised in the all layers of the capsule is used for food additive in Japan. Wang et al. [23] reported that the titanium was accumulated in the spleen and brain when female mice were one time administrated $5 \mathrm{~g} /$ $\mathrm{kg}$ body weight of fine-sized titanium dioxide suspensions, but showed no acute toxicity. In the present study, orally administrated titanium dioxide was approximately $0.08 \mathrm{mg} /$ $\mathrm{kg}$ body weight of cattle. We concluded that the capsule in itself is harmless to cattle and products. In addition, we con-
Table 1. Dietary ingredients and chemical composition

\begin{tabular}{lc}
\hline & \% Dry matter \\
\hline Ingredients & \\
Timothy hay & 35.0 \\
Oats hay & 15.0 \\
Alfalfa hay & 10.0 \\
Beet pulp & 10.0 \\
Commercial concentrate ${ }^{\mathrm{a})}$ & 30.0 \\
Chemical composition $^{\text {b) }}$ & \\
Crude protein $^{\text {Estimated TDN }}$ & 12.8 \\
\hline
\end{tabular}

a) Commercial concentrate containing the following ingredients: heated corn grain, wheat flour, toasted soybean flour, defatted soymeal, rapeseed oil cake, sesame-seed oil cake, corn gluten, wheat bran, sugar beet molasses, calcium carbonate, dehydrated alfalfa meal, calcium phosphate, sodium chloride and supplement (vitamin A, vitamin D3, vitamin E, ferric sulfate, copper sulfate, zinc sulfate, manganese sulfate, cobalt sulfate, magnesium carbonate, calcium iodate, magnesium oxide and methionine compound). b) TDN, total digestible nutrient. Based on NARO [16].

firmed that specific gravity of the capsule can be adjusted by using talc (which is authorized feeding to cattle) in exchange for titanium dioxide.

In vitro incubation of capsules and preliminary administration: Twenty particles of manufactured capsules per flask were anaerobically incubated by shaking in $100 \mathrm{ml}$ rumen liquor at $39^{\circ} \mathrm{C}$ for $24 \mathrm{hr}$ in triplicate. Rumen liquor was obtained from lactating cows via rumen catheter and was immediately used for in vitro incubation of the capsules. Twenty-four hr later, capsules were recovered using a 2.0-mm screen. Visual inspection established whether or not the capsules had undergone lysis in the rumen liquor. Before the main test, the rumen insoluble capsules were preliminarily administered to cows in order to examine the effect of the breaking strength of the capsules on their solubility in the lower digestive tract subsequent to the rumen in vivo. Two cows were orally administered the capsule with five kinds of breaking strength $(0.9,2.5,4.1,5.4$ and $8.1 \mathrm{~N})$ every other week. All feces were picked up from the floor after administration for $24 \mathrm{hr}$, and the status of excreted capsules was checked visually. A rheometer (CR-500DX, Sun Scientific Co., Ltd., Tokyo, Japan) was used to measure the breaking strength of the capsule, and the breaking strength was defined as the breaking load when the capsule broke due to constriction. The measurement was carried out using a pressure sensitive disc-shaped shaft with a diameter of $10 \mathrm{~mm}$, moving at $20 \mathrm{~mm} / \mathrm{min}$ at $39^{\circ} \mathrm{C}$.

Administration of capsules containing water-soluble vitamins: Thiamine hydrochloride was used to determine whether the capsules successfully escaped the rumen. The capsules contained a core of thiamine hydrochloride (Wako Pure Chemical Industries, Ltd., Osaka, Japan). The test group was administered encapsulated thiamine hydrochloride, whereas the control group was administered the same amount of thiamine hydrochloride in an aqueous solution. Both the test and control groups were orally administered $30 \mathrm{~g}$ of thiamine hydrochloride (approximately 1,500 capsules for test group) per head. A polyvinyl chloride resin 

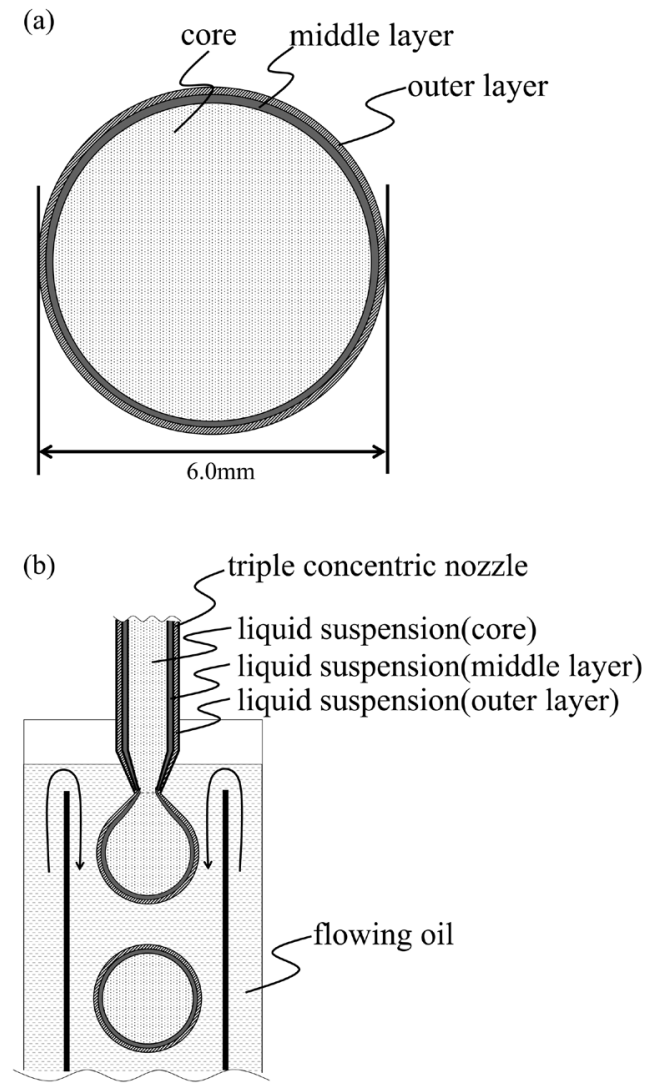

Fig. 1. Schematic of (a) the three-layered capsule and (b) method of manufacture. (a) Core: a mixture of hydrogenated palm oil and water-soluble vitamins, including titanium dioxide as a densityadjusting agent. Middle layer: composed of hydrogenated oils and titanium dioxide. Outer layer: consists of starch, carrageenan and so on. Diameter is $6 \mathrm{~mm}$, and specific gravity is 1.3 . (b) Triple concentric nozzle: core, middle and outer liquid suspension were obtained from respective nozzle. Liquid suspension: three kinds of liquid suspension of core, middle layer and outer layer. Core liquid included substances intended to be escaped rumen. Flowing oil: carrier of spherical droplets.

installer RUMENFIBE (Meiwa Sangyo Co., Ltd., Kyoto, Japan) was used for oral administration. Administration of both the capsules and solution was forced at 10:00 prior to feeding. Blood samples were collected from the jugular vein every $3 \mathrm{hr}$, from immediately before administration until $24 \mathrm{hr}$ after administration. All urine was collected by urinary catheterization for $24 \mathrm{hr}$ after administration and weighed after each excretion. Then, $2 \mathrm{~m} l$ of urine was immediately stored at $-20^{\circ} \mathrm{C}$ until analysis.

The thiamine concentration was measured using the modifications by Fukuwatari et al. [7] to the high-performance liquid chromatography (HPLC) method by Kimura et al. [10]. Specifically, for blood samples, $300 \mu l$ of whole blood was taken using sodium heparin as an anticoagulant, to which $600 \mu \mathrm{l}$ of $5 \% \mathrm{w} / \mathrm{v}$ trichloroacetic acid solution was added. This mixture was then centrifuged at 15,000 $\times g$ and $4^{\circ} \mathrm{C}$. The supernatant was used as an HPLC injection sample following filtration. Following column separation using $0.2 \mathrm{M}$ sodium dihydrogen phosphate $/ 0.3 \% \mathrm{v} / \mathrm{v}$ acetonitrile as the mobile phase, it was mixed with $0.1 \% \mathrm{w} / \mathrm{v}$ potassium ferricyanide and $15 \% \mathrm{w} / \mathrm{v} \mathrm{NaOH}$ before measurement using a fluorescence detector. The columns were reversed-phase HPLC columns (COSMOSIL 5C18-MS-II, $4.6 \times 250 \mathrm{~mm}$, NACALAI TESQUE, Inc., Kyoto, Japan).

Statistical analysis: For samples collected concurrently, Student's $t$-test was used to examine inter-group differences in blood thiamine concentrations. Tukey's multiple comparison analysis was used to determine differences in the concentrations of blood thiamine within each group. All analyses were performed using $\mathrm{R}$ statistical software (version 3.1.0; www.r-project.org). Results were considered significant at $P<0.05$.

\section{RESULTS}

In vitro incubation of capsules and preliminary administration: For in vitro incubation, there were no lysed capsules in the rumen liquor for $24 \mathrm{hr}$. When the capsules with a breaking strength of $4.7 \mathrm{~N}$ were orally administrated to cattle, the capsules were excreted having maintained their spherical shape in feces (Table 2). On the other hand, only fragments of the capsule were obtained from the feces when capsules with breaking strength of $4.1 \mathrm{~N}$ or less were administrated. So, we used capsules with a breaking strength of $4.1 \mathrm{~N}$ in the subsequent experiments.

Administration of capsules: The results of thiamine hydrochloride level in the blood are shown in Fig. 2. No change in blood thiamine concentrations was found in the control group that was administered an aqueous solution of thiamine hydrochloride. In contrast, in the test group administered thiamine hydrochloride via the three-layer capsules, a marked rise in blood thiamine concentration was found 3 $\mathrm{hr}$ following administration. The concentration significantly increased from $12.4 \pm 1.03 \mathrm{ng} / \mathrm{m} l$ before administration to $54.8 \pm 2.21 \mathrm{ng} / \mathrm{ml}$ at $6 \mathrm{hr}$ after administration. The elevated blood thiamine concentration was maintained for $9 \mathrm{hr}$ after administration before gradually decreasing. Blood concentrations were 4.1-fold higher in the test group than in the control group $6 \mathrm{hr}$ after administration. Figure 3 shows accumulated thiamine hydrochloride excreted in urine, calculated from urine thiamine hydrochloride level and urine volume after administration of capsules. There was considerable individual variability in the thiamine value, and no difference was found between the test group $(801.7 \pm 348.2 \mu \mathrm{g})$ and the control group $(674.6 \pm 184.1 \mu \mathrm{g}, P=0.7993)$ at $24 \mathrm{hr}$ after administration.

\section{DISCUSSION}

There were no lysed capsules in in vitro incubation, and hence, it was concluded that capsules placed into the rumen retained their shape until flowing out to the omasum. Our previous study in dairy cattle showed that the proportion of ruminated indigestible plastic balls (which are similar to the capsules used in this study in shape, size and specific grav- 
Table 2. Status of capsules after in vitro incubation and preliminary administration

\begin{tabular}{lccccc}
\hline Breaking strength of a capsule $(\mathrm{N})$ & 0.9 & 2.5 & 4.1 & 5.4 & 8.1 \\
\hline $\begin{array}{l}\text { Status of capsules after } \text { in vitro incubation } \\
\text { Status of capsules in feces }\end{array}$ & $\begin{array}{c}\text { Spherical shape } \\
\text { Fragment }\end{array}$ & $\begin{array}{c}\text { Spherical shape } \\
\text { Fragment }\end{array}$ & $\begin{array}{c}\text { Spherical shape } \\
\text { Fragment }\end{array}$ & $\begin{array}{c}\text { Spherical shape } \\
\text { Spherical shape }\end{array}$ & $\begin{array}{l}\text { Spherical shape } \\
\text { Spherical shape }\end{array}$ \\
\hline
\end{tabular}

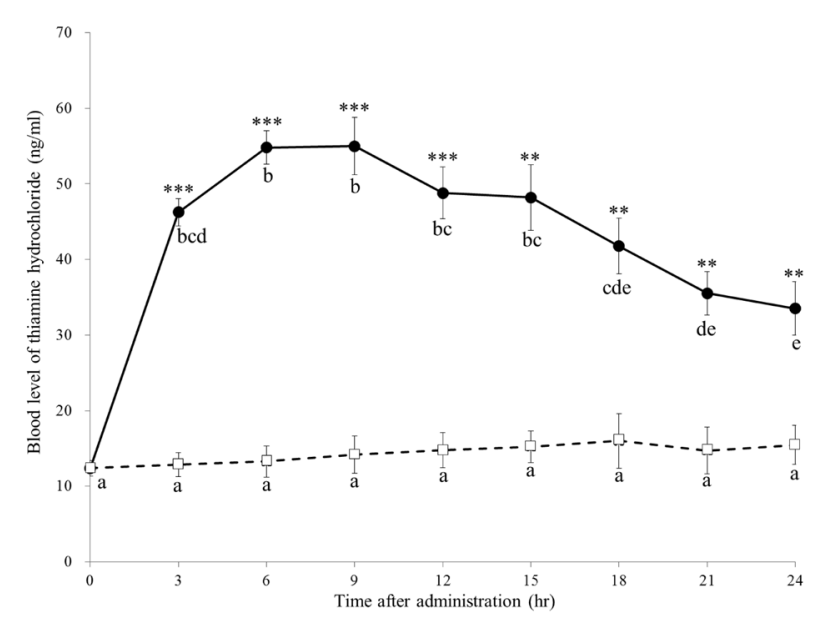

Fig. 2. Changes in blood thiamine hydrochloride concentration. Blood thiamine concentrations were measured before administration and every $3 \mathrm{hr}$ after administration. $\bullet$ : Encapsulated thiamine hydrochloride-administered group, $\square$ : aqueous thiamine hydrochloride-administered group. *: denotes significant differences between the groups at the given time $(* *, P<0.01$; ***, $P<0.001)$. $\mathrm{a}, \mathrm{b}, \mathrm{c}, \mathrm{d}, \mathrm{e}$ : Significant differences between time periods are noted with different letters $(P<0.05)$.

ity) was $2 \%$ or less [19]. According to that finding, almost all the capsules possibly passed through the rumen without being degraded by microorganisms in rumen and/or physical destruction by rumination. In the present study, the capsules were found to be insoluble in rumen liquor in vitro. At the same time, no intact capsules were found in feces after the preliminary administration when the breaking strength of capsule was set for less than $4.1 \mathrm{~N}$. In addition, we have reported in our previous study that oral administration of the same three-layered capsules containing live lactic acid bacteria had altered the intestinal bacterial flora of cattle [20]. These results strongly suggest that the capsules used in the main administration tests in this study escaped from being broken in the rumen, but dissolved in lower digestive tract.

The elevated blood thiamine concentration in the test group suggests that the capsule reached the intestinal tract after passing quickly through the anterior stomach. It has been suggested that solids with a high specific gravity, such as the capsules used in this study, quickly enter the ruminal ventral sacs rather than being limited to the mat formed in the rumen [6]. Additionally, it is known that once solids have entered the ventral sac, they flow through the omasum without reentering the dorsal sac [17]. Hoeller et al. [8] reported that the rumen wall of sheep has an extremely low permeability to thiamine and that the rumen may not be a site of significant absorption of thiamin. Moreover, Miller

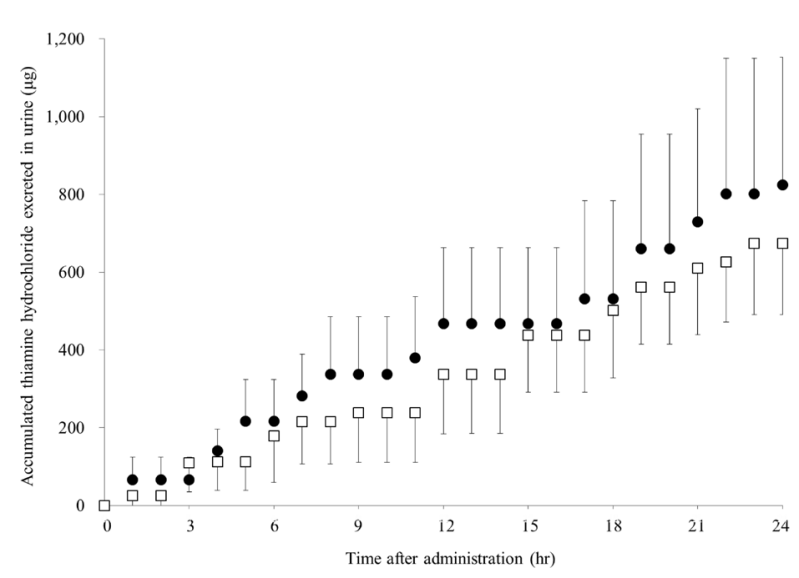

Fig. 3. Accumulated thiamine hydrochloride excreted via urine, calculated from the concentration and volume of each urine excretion. All urine was collected for $24 \mathrm{hr}$ after administration and weighed immediately. Each plot shows average accumulated thiamine hydrochloride in urine for the time elapsed since administration. -: Encapsulated thiamine hydrochloride -administered group, $\square$ : aqueous thiamine hydrochloride -administered group. Error bars represent the standard error of the mean.

et al. $[12,13]$ reported that absorption of thiamine occurs mainly in the small intestine. In the results of our study, the blood thiamine levels started to increase $3 \mathrm{hr}$ after administration in the test group, even though thiamine half-life in blood is very short, reported as 4.7 and $7.1 \mathrm{~min}$ in fitting two exponential functions [22]. Furthermore, plasma thiamine concentration peaked between 6 and $9 \mathrm{hr}$ after administration before subsequently starting to decline. These results suggest that the capsules moved rapidly to the duodenum without stopping in the rumen; and that almost all the capsules had dissolved and released their contents in a rapid manner, since no capsules lysed in rumen liquor in in vitro incubation, as indicated above. The rise of blood thiamine level for the test group seems to be relatively low with respect to the amount of administered thiamine. It is thought to be due to that thiamine is quickly metabolized in blood and its half-life is very short [22].

In contrast, the ruminal retention time of the aqueous solutions, such as those used in the control group, is estimated to be about $10 \mathrm{hr}$ in dairy cows [14]. Assuming that as much as $52 \%$ administered thiamine hydrochloride reached the lower digestive tract intact [24], a rise in blood concentrations would be expected to occur $10 \mathrm{hr}$ following administration. However, in practice, this was not observed. This is considered to be due to metabolic action of ruminal microorganisms and/or quick hydrolysis or tissue uptake that somewhat 
absorbed thiamin, as mentioned above. With regard to urine, there was no difference in accumulated thiamine hydrochloride between control and test groups. Nakajima et al. [15] reported that in cattle, thiamine is absorbed from blood by some tissues, such as the brain, heart, liver and kidney. For this reason, it was concluded that tissue uptake of migrated thiamine from capsules occurred in a matter of hours and that thiamine was not excreted to urine.

The above results show that encasing water-soluble vitamins within a multi-layer capsule structure allows for efficient absorption by cows. The three-layered capsules developed in this study for cows were shown to function as a rumen escapable tool. Additionally, it was demonstrated that the capsules rapidly moved to the duodenum following administration, since peak blood thiamine concentration occurred between 6 and $9 \mathrm{hr}$ after oral capsule administration.

Thiamine is effective for prevention and treatment of bovine ketosis, but has been administered intravenously because it is degraded in the rumen. Our present work suggests that the three-layered capsule presented here could enable oral administration of thiamine to cattle, which is easier than intravenous injection on-site. Furthermore, capsules could be used in cases where the bypass oil method is not available, such as for medical products, probiotics or transmucosally administered vaccines that have little resistance to heat or acid. A further study is required for more detailed evaluation of the capacity of three-layered capsules, such as the escape efficiency of capsules and quantification of the rumen escape level of contents for clinical veterinary use.

ACKNOWLEDGMENTS. This work was supported by the Adaptable and Seamless Technology Transfer Program through target-driven R\&D, Japan Science and Technology Agency. The authors also acknowledge the support of Morishita Jintan Co. Limited (Osaka, Japan) for the donation of techniques to manufacture the seamless capsules.

\section{REFERENCES}

1. Adachi, T., Seyama, T., Hirayasu, H., Kasai, K. and Fujitani, Y. 2015. Orally administered agent for ruminants and ruminant feed containing same. Japanese Patent Application No.017200, PCT/JP2015/052754, WO2015/115618, 6 August 2015.

2. Asada, M., Kanaya, T., Ogawa, T., Shimada, M. and Uehara, Y. 2015. Method for inhibition of blood phosphorus level elevation. US Patent No.09056122, granted 16 June 2015.

3. Chalupa, W. 1975. Rumen bypass and protection of proteins and amino acids. J. Dairy Sci. 58: 1198-1218. [Medline] [CrossRef]

4. Collard, B. L., Boettcher, P. J., Dekkers, J. C., Petitclerc, D. and Schaeffer, L. R. 2000. Relationships between energy balance and health traits of dairy cattle in early lactation. J. Dairy Sci. 83: 2683-2690. [Medline] [CrossRef]

5. Duffield, T. 2000. Subclinical ketosis in lactating dairy cattle. Vet. Clin. North Am. Food Anim. Pract. 16: 231-253, v. [Medline] [CrossRef]

6. Faichney, G. 1980. Measurement in sheep of the quantity and composition of rumen digesta and of the fractional outflow rates of digesta constituents. Aust. J. Agric. Res. 31: 1129-1137. [CrossRef]

7. Fukuwatari, T., Suzuura, C., Sasaki, R. and Shibata, K. 2004.
[Action site of bisphenol A as metabolic disruptor lies in the tryptophan-nicotinamide conversion pathway]. Shokuhin Eiseigaku Zasshi 45: 231-238. [Medline] [CrossRef]

8. Hoeller, H., Fecke, M. and Schaller, K. 1977. Permeability to thiamin of the sheep rumen wall in vitro. J. Anim. Sci. 44: 158-161. [Medline] [CrossRef]

9. Kamaguchi, R., Shiomi, T. and Uehara, Y. 2007. Non-gelatinous capsule shell composition and a capsule formed from the same. US Patent No. 7255921, granted 14 August 2007.

10. Kimura, M., Fujita, T. and Itokawa, Y. 1982. Liquid-chromatographic determination of the total thiamin content of blood. Clin. Chem. 28: 29-31. [Medline]

11. Kossaibati, M. A. and Esslemont, R. J. 1997. The costs of production diseases in dairy herds in England. Vet. J. 154: 41-51. [Medline] [CrossRef]

12. Miller, B. L. and Meiske, J. C. 1986. Effects of dietary additives on B-vitamin production and absorption in steers. J. Anim. Sci. 62: 484-496. [CrossRef]

13. Miller, B. L., Meiske, J. C. and Goodrich, R. D. 1986. Effects of grain source and concentrate level on B-vitamin production and absorption in steers. J. Anim. Sci. 62: 473-483. [CrossRef]

14. Miyaji, M., Oshita, T., Aoki, Y., Nakamura, M., Aoki, M., Ueda, Y., Nishiura, A., Takusari, N. and Ito, F. 2009. Ruminal capacity, and digesta weight and retention time in the different segment of primiparous Holstein dairy cows in early lactation at ad libitum feeding. Nihon Chikusan Gakkaiho 80: 457-463. [CrossRef]

15. Nakajima, N., Ichijo, S., Sarashina, T. and Osame, S. 1984. Studies on the metabolism of thiamine in cattle. Blood level and urinary excretion after intravenous administration of thiamine preparations. J. Jpn. Vet. Med. Assoc. 37: 99-103. [CrossRef]

16. National Agriculture and Food Research Organization (NARO) 2009. Japanese Feeding Standard for Daily Cattle. Japan Livestock Industry Association, Tokyo.

17. Poppi, D. P., Ellis, W. C., Matis, J. H. and Lascano, C. E. 2001. Marker concentration patterns of labelled leaf and stem particles in the rumen of cattle grazing bermuda grass (Cynodon dactylon) analysed by reference to a raft model. Br. J. Nutr. 85: 553-563. [Medline] [CrossRef]

18. Rauw, W., Kanis, E., Noordhuizen-Stassen, E. and Grommers, F. 1998. Undesirable side effects of selection for high production efficiency in farm animals: a review. Livest. Prod. Sci. 56: 15-33. [CrossRef]

19. Seyama, T., Hirayasu, H. and Kasai, K. 2016. Excretion rates of indigestible plastic balls of different specific gravities and diameters in dairy cattle. Anim. Sci. J. (In press). [Medline] [CrossRef]

20. Seyama, T., Hirayasu, H., Yoshida, G., Ohnuma, A., Qiu, Y., Nakajima, C., Kasai, K. and Suzuki, Y. 2016. The effects of administering lactic acid bacteria sealed in a capsule on the intestinal bacterial flora of cattle. Jpn. J. Vet. Res. 64: 197-203.

21. Shaw, J. 1946. Studies on ketosis in dairy cattle. VII. The efficacy of B vitamins and methionine in the treatment of ketosis. J. Dairy Sci. 29: 131-139. [CrossRef]

22. Thornber, E. J., Dunlop, R. H., Gawthorne, J. M. and Huxtable, C. R. 1981. Induced thiamin deficiency in lambs. Aust. Vet. J. 57: 21-26. [Medline] [CrossRef]

23. Wang, J., Zhou, G., Chen, C., Yu, H., Wang, T., Ma, Y., Jia, G., Gao, Y., Li, B., Sun, J., Li, Y., Jiao, F., Zhao, Y. and Chai, Z. 2007. Acute toxicity and biodistribution of different sized titanium dioxide particles in mice after oral administration. Toxicol. Lett. 168: 176-185. [Medline] [CrossRef]

24. Zinn, R. A., Owens, F. N., Stuart, R. L., Dunbar, J. R. and Norman, B. B. 1987. B-vitamin supplementation of diets for feedlot calves. J. Anim. Sci. 65: 267-277. [Medline] [CrossRef] 